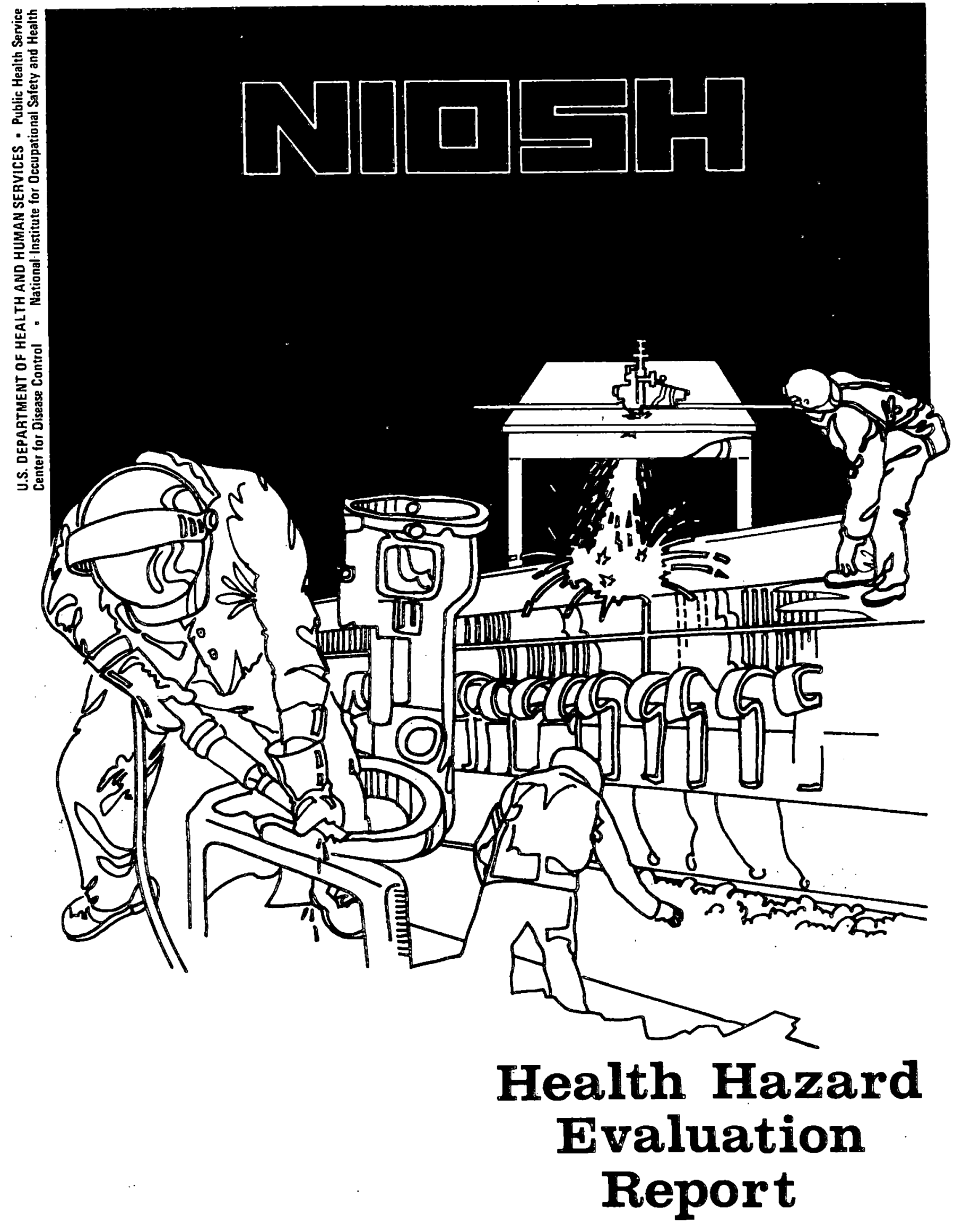

$79-17-751$ 
PREFACE

The Hazard Evaluations and Technical Assistance Branch of NIOSH conducts field investigations of possible health hazards in the workplace. These investigations are conducted under the authority of Section 20(a)(6) of the Occupational Safety and Health Act of 1970, 29-U.S.C. 699(a)(6), which authorizes the Secretary of Health and Human Services, following a written request from any employer or authorized representative of employees, to determine whether any substance normally found in the place of employment has potentially toxic effects in such concentrations as used or found.

Mention of company names or products does not constitute endorsement by the National Institute for Occupational Safety and Health. 
HE $79-17-751$

October 1980

RMI Metals Reduction Plant

Ashtabula, Ohio
NIOSH Investigators:

Clifford Moseley, IH

David Garabrant, MD

Lawrence Fine, MD

I. SUMMARY

On October 30, 1978, the Oil, Chemical, and Atomic Workers International Union requested a health hazard evaluation of workers at RMI Metals, Ashtabula, Ohio involved in titanium sponge metal production. This study was requested because of a reported high incidence of pulmonary fibrosis among these workers.

NIOSH conducted two site visits on January 8-9 and June 25-28, 1979, in order to conduct environmental sampling and perform a medical evaluation of the work population. Personal and area air sampling for airborne contaminants, and a review of work practices and working conditions were performed. Work and health history questionnaires, and physical exams, including pulmonary function tests and chest $x$-rays, were administered to selected workers.

With the exception of one total particulate and two respirable particulate samples, air sampling for titanium, considered as a nuisance particulate, showed concentrations to be below published criteria listed in Table I. The three samples that exceeded recommended exposure criteria were $11.6 \mathrm{mg} / \mathrm{M}^{3}$ total nuisance dust, and 6.6 and $7.0 \mathrm{mg} / \mathrm{M}^{3}$ respirable nuisance particulate. Samples for welding fume and hydrochloric acid were below recommended criteria. Airborne asbestos was not detected.

The medical study revealed a high prevalence of chest $x$-ray and pulmonary function abnormalities. Production and non-production workers showed different patterns of $x$-ray changes. Extensive pleural thickening was present in 168 of the 58 non-production workers (maintenance, service, etc.) and was most prevalent among those who had worked at RMI for at least ten years. Limited pleural thickening was found in 148 of the 151 production workers employed between 1957 and 1968. The major pulmonary function changes were among the titanium tetrachloride reduction process workers who showed restrictive pulmonary changes with a significant Yearly loss of lung volume (45 cc/year) even when adjusted for the effects of smoking.

On the basis of the evaluation, a health hazard of pulmonary impairment exists at RMI. Although the environmental and medical data could not clearly identify a cause, past exposure to asbestos and past and/or current exposure to titanium compounds appear to be most likely responsible for the pulmonary impairment. Recommendations concerning limiting employee exposures to workplace contaminants, and the development of an environmental and medical surveillance program, are presented on pages 9-1l of this report.

Keywords: SIC 3339 (titanium sponge), titanium, titanium tetrachloride, asbestos, welding fumes, pulmonary disease, pleural thickening. 
II. INTRODUCTION

On October 30,1978 , an international representative of the Oil, Chemical, and Btomic Workers Union requested a health hazard evaluation on behalf of Local 7-629, Ashtabula, Ohio. The request indicated concern about employee exposure to salt, sodium, titanium metal dust, and titanium tetrachloride at the RMI Metals Reduction Plant. A medical study was also requested because of the reported high incidence of pulmonary fibrosis among workers.

An interim report, dated February 8,1979 , detailing the findings of the initial site visit and the protocol for the follow-up evaluation, was provided to the company and union.

Interim environmental sampling results of the follow-up study were provided in two letters dated August 10 and September 21, 1979.

\section{BACKGROUND INFORMATION}

A. Description of Process

RRI Metals Reduction Plant makes titanium sponge metal, an intermediary in the production of titanium metal, which is used in the aerospace and medical industries because of its high tensile strength, light weight, and heat resistant properties. The plant has been in operation since 1957. In addition, zirconium metal was also produced until 1962.

The manufacturing process involves reacting titanium tetrachloride $\left(\mathrm{TiCl}_{4}\right)$, which is piped in from an adjacent tank farm in an enclosed system, with liquid sodium metal to produce titanium metal, in a porous, sponge-like form. Large ( 6 feet by 10 feet) sinter pots are used as the reactor vessels. The reaction is carried out under slightly positive inert gas pressure to exclude contaminants such as oxygen, nitrogen, and water vapor. The reaction is driven to completion by heat in the sintering furnace. The pots are transported to a cooling area and the tops are subsequently removed with an automatic oxyacetylene cutting torch. The opened pots are taken to one of two chipping decks where large automatic chipping guns are used to remove the reactor product "spalt". The spalt is crushed, passed through a sizing screen onto a conveyor which carries it through a dilute $\mathrm{HCl}$ bath to remove the salt. The titanium sponge metal is then washed with warm water, centrifuged to remove moisture and fine particulate, and dried. Drying is by vacuum, either continuous or batch mode. The finished product is packed in drums or other containers for shipment. 
Page 3 - Health Hazard Evaluation Determination Report HE 79-17

The sinter pots are reused. After being emptied on the chipping deck, they are washed in large enclosures which use pressurized hot water and soap. After the tops are welded back on, they are taken to the loading or charging area, where the sodium metal and $\mathrm{TiCl}_{4}$ are added.

Approximately 10 sinter pots are processed per shift. Figure I illustrates the titanium sponge manufacturing process and the potential exposures at each step.

B. Work force

The work force consists of 140 production workers; 90 maintenance, service, and janitorial workers; and 24 salaried workers. The company operates 4 rotating shifts, 7 days a week. See Figure 1 .

c. Other

For an unknown period in the past, asbestos was used as a heat shield (drape type) in the sintering furnace area, and as a wrap for piping. However, the Company stated that all asbestos use had been discontinued in 1976. An asbestos containing spray-on insulating material had been used on the walls of the pot cooling area. This insulation is still in place.

IV. HAZARD EVALUATION DESIGN

\section{A. Evaluation Criteria and Health Effects Data}

Exposure criteria have been developed to evaluate a workers' exposure to toxic substances in an occupational setting. Based on available human and animal studies, and industrial experience, these values represent levels to which it is believed that nearly all workers may be exposed for an 8 hour day, 40 hour workweek, throughout a working lifetime without adverse effects. Table I lists the substances of concern in this hazard evaluation, the recommended exposure criteria and their source, and comments on the known health effects of each substance.

B. Materials and Methods

1. Environmental

In order to determine if the workplace environment was responsible for the reported health complaints, an industrial hygiene survey was performed. This survey consisted of air sampling, analysis of bulk process samples, and evaluation of engineering controls and work procedures. Personal breathing zone air samples were collected for titanium compounds (except $\mathrm{TiCl}_{4}$ ) and welding fumes. Area samples were collected for asbestos and $\mathrm{HCl}$. Air sampling and laboratory analysis for the substance listed in Table I was conducted according to standard NIOSH methods (7), listed in Table II. 
Note that the recommended exposure criteria for titanium is the same as that for nuisance particulate. Due to the lack of definitive toxicological information on titanium, for the purposes of this study, employee exposure to titanium will be compared to the nuisance dust criteria.

\section{Medical}

In order to identify any health effects present in the RMI work force, a medical study was conducted. The work force was divided into exposure groups based on work assignment throughout their employment at RMI. The entire population examined was labeled Group I. This group was divided into workers who spent less than six months in production

(non-production workers, or Group 2) and workers who spent six months or more in any production job (production workers, or Group 3). The non-production workers would include maintenance, service, janitorial, etc. workers. The production workers (Group 3) were in turn divided into workers who spent six months or more in the tit...iijm tetrachloride reduction processes (Group 4) and workers who spent less than six months in these areas (Group 5). The titanium tetrachloride reduction process involved two steps: The first reacted titanium tetrachloride with liquid sodium to produce titanium dichloride. The second heated this $\mathrm{TiCl}_{2}$ in sinter pots to produce titanium metal. These two production areas are adjacent and share most occupational exposures from these processes. For the purposes of initial analyses, these work groups were combined into a single group. This group includes the P4 and P5A designation in Figure $I$.

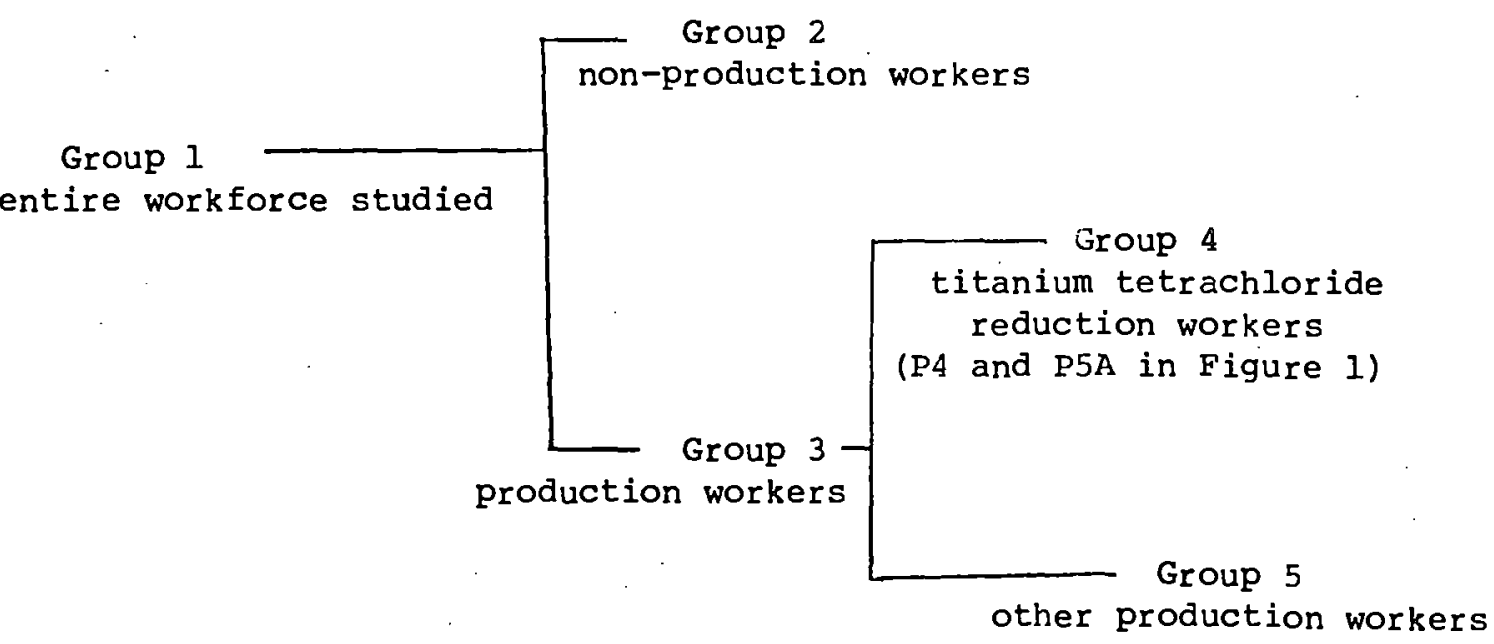

The scheme allowed comparison of all production workers with all non-production workers, allowed comparison between production groups having different exposures, and allowed comparison between non-production workers and different production groups. It should be noted that these groups are not mutually exclusive; i.e. a worker may be included in more than one group. 
Page 5 - Health Hazard Evaluation Determination Report HE 79-17

Each employee underwent physical examination of the heart and lungs by a physician and health history interviewing. The interview focused on past medical history related to pulmonary disease, present respiratory symptoms, smoking history, occupational history, and family history of respiratory disease. Detailed occupational histories were obtained from company work records; job titles and dates of work in each area of the plant were recorded, as well as a history of all previous employers and dates of employment for each individual.

Radiographs - Chest x-rays were obtained on all 209 workers. One hundred thirty-five workers had technically adequate chest $x$-rays taken during an annual physical examination between June 1978 and March 1979.

Seventy-four individuals had chest $x$-ray taken during June 26-29, 1979, because they had inadequate previous chest $x$-rays or had abnormalities on previous $x$-rays. X-rays were read by a physician certified as "reader B" by the National Institute for Occupational Safety and Health using the ILO U/C 19.71 International Classification of Radiographs of the Pneumoconioses (8). Small rounded opacities and small irregular opacities were classified by size and by profusion. Pleural thickening was classified by site, width, and extent.

Pulmonary Function Tests - The ventilatory capacities were measured with a spirometer meeting the American Thoracic Society instrument specifications (9). The FVC was measured repeatedly until at least three acceptable curves were obtained, such that the two best of the three acceptable curves did not vary by more than $\pm 5 \%$. Ninety-eight percent of the subjects met this criterion. The FVC was taken as the average of the three best curves. The $\mathrm{FEV}_{1}$ was taken as the average of the FEV 1 as read on the same three curves. Predicted values for FVC and $\mathrm{FEV}_{1}$ were those of Knudson et al (10), and Fine and Peters (11).

Statistical Analysis - The data were processed on the Harvard-MIT Itel AS/5 computer using programs described in IBM Virtual Machine

Facility/370: CMS User's Guide (12) and Statistical Package for the Social Sciences:SPSS (13).

V. RESULTS

A. Environmental

The results of the air samplings are presented in Tables III and IV. Table III contains total and respirable particulate data. One sample exceeded the recommended criteria for total particulate. Two samples exceeded the respirable dust criteria. The more heavily exposed job classifications are chippers and maintenance men (during packing gland changing). 
Welding data are in Table IV. No samples exceeded the recommended criteria of $5 \mathrm{mg} / \mathrm{M}^{3}$ (iron oxide).

The remaining air samples can be summarized briefly:

1. Two area impinger samples for $\mathrm{HCl}$ were taken in both leaching areas. The calculated concentrations are 0.47 and $0.15 \mathrm{mg} \mathrm{HCl} / \mathrm{M}^{3}$. These values are below the recommended criteria of $7 \mathrm{mg} / \mathrm{M}^{3}$. If a worker were to spend all shift in proximity to the HCl air sampling stations, he would not be exposed excessively to $\mathrm{HCl}$ mist.

2. Four activated charcoal air samples were taken during packing gland change operations to determine if employees were exposed to any organic compounds during this procedure. No organic compounds were detected. In addition, a bulk sample of the packing material was analyzed for heat decomposition products. At $375^{\circ} \mathrm{F}$, acetone, acetaldehyde, cyclobutane, butene, furan, methyl furan, formaldehyde, and methyl furfural were detected. No compounds were detected at $250^{\circ} \mathrm{F}$. While some of these compounds are known to be respiratory irritants, the heat of the process does not approach $375^{\circ} \mathrm{F}$. Therefore, these compounds are not expected to pose a health problem under ordinary circumstances.

3. Four high volume filter samples for airborne asbestos fibers and identification of other airborne particulates were taken in selected locations. All samples for asbestos fibers were negative. Traces of iron, titanium, silicon, aluminum, potassium, calcium, sulfur, and probably salt were detected. In addition, a bulk sample of insulating material from the walls of the pot cooling area was analyzed for asbestos. Analysis indicated 40-70\% chrysotile asbestos and 5-10\% mineral wool.

B. Medical

\section{Demographic Characteristics of Exposure Groups}

The demographic characteristics of the exposure groups are presented in Table v. Non-production workers were older than production workers, had smoked longer, and had worked longer in the presence of asbestos before joining RMI. The average height and average duration of work at RMI were essentially uniform for all five groups. The two production groups (Groups $4 \& 5$ ) were essentially identical in terms of age, height, years smoked, and past work with asbestos. The titanium tetrachloride reduction workers (Group 4) worked longer in production than other production workers. The latter worked longer in non-production. 
2. Respiratory Symptoms and Physical Examination Findings

The prevalence of respiratory symptoms (Table VI) was slightly higher among production than among non-production workers. However, none of the differences were statistically significant. Physical examination (Table VII) revealed abnormal breath sounds in $5 \%$ of the titanium tetrachloride reduction workers (Group 5) and 168 of the other production workers (Group 4) (p .02). However, specific abnormalities were infrequently heard.

\section{Pleural Thickening}

Pleural thickening was found in 178 of the study group, with a higher prevalence among non-production workers than among production workers. Extensive pleural thickening was present in 168 of non-production workers (Group 2) and in $2 \%$ of production workers (Group 3). Limited pleural thickening was present in $5 \%$ of non-production workers and 148 of production workers. The non-uniformity of the distribution of pleural thickening among job groups led to further analysis to determine whether particular jobs carried a high risk of pleural thickening. A series of two by two tables were constructed and prevalence odds ratios were calculated for each exposure group compared to a non-exposed group.

Pleural thickening was found to be strongly associated with employment at RMI of at least five years duration; the risk of pleural thickening increased with the number of years worked.

Analysis by job group demonstrated the risk of pleural thickening to be higher among workers with at least five years of experience in non-production jobs than among workers with at least five years experience in production jobs. There was no significant risk associated with production jobs.

Pleural thickening was next divided into two categories of severity. Limited pleural thickening comprised thickening of less than $5 \mathrm{~mm}$ thickness and less than $1 / 2$ the length of the chest wall in extent and pleural plaques, and extensive pleural thickening comprised all thickening of at least $5 \mathrm{~mm}$ thickness or exceeding $1 / 2$ the length of the chest wall. There were 24 cases of limited pleural thickening and 12 cases of extensive pleural thickening. 
Limited pleural thickening was significantly associated with at least 5 years employment at RMI, particularly in the old titanium production area (P5). This job group existed only from 1957, when the plant opened, until 1968, when it was split into two separate job groups. The absence of pleural thickening among recent workers may be due to the shorter time since first exposure, or due to changes in work practices since 1968. The workers from the old titanium production area had no increased risk of developing extensive pleural thickening, suggesting that limited pleural thickening and extensive pleural thickening may represent different pathological processes or may result from different exposures.

Extensive pleural thickening was significantly associated with at least 10 years employment at RMI and was more strongly associated than limited thickening. Analysis by job group revealed a strong association between work in non-production areas and the presence of extensive pleural thickening. This association became progressively stronger after ten and fifteen years of work in non production. There was no significant association between extensive pleural thickening and work in any production area.

A different exposure pattern was seen among workers with limited pleural thickening. The risk of developing these changes was elevated among men employed in production between 1957 and 1968. No other production groups or non-production group had an elevated risk. Furthermore, the production group with the highest risk of limited pleural thickening had no significant risk of developing extensive pleural thickening. Many of these men had been employed since the plant opened in 1957 and had the longest latency times since first exposure.

It did not appear that the pleural thickening was responsible for changes in pulmonary function as no association was found between pleural thickening and any measure of dynamic lung volume.

\section{Pulmonary Function Testing}

Extensive analysis of the plumonary function data was performed. A detailed description of the analysis is included in the full medical report which is available on request from Hazard Evaluations and Technical Assistance Branch. 
Page 9 - Health Hazard Evaluation Determination Report HE 79-17

Two specific items were looked at: forced vital capacity (FVC) and forced expiratory volume in 1 second $\left(\mathrm{FEV}_{1}\right)$. FVC is a measure of the amount of air you can force out of your lungs after breathing in as deeply as you can. $\mathrm{FEV}_{1}$ measures the amount of air you can breathe out in the first second. The values measured in the study were compared to predicted values obtained from general population outside RMI.

The mean FVC and mean $\mathrm{FEV}_{1}$ were less than predicted for this population. Non-production workers were affected more than production workers. Among production workers, titanium tetrachloride reduction workers (Group 4) were affected more than other production workers (Group 5). This pattern held even after the data were corrected for smoking. Thus this differential loss appears to be related to different job exposures at RMI.

In order to determine what effect prolonged work exposure in production had on pulmonary function, the study population was divided into the following groups for comparison:

a. Control - individuals having no more than 2 years employment at RMI .

b. Group A - individuals having at least 10 years employment in non-production jobs (maintenance, janitorial, service, etc.)。

c. Group B - individuals having at least 10 years employment in production jobs.

d. Group C - individuals having at least 10 years employment in the titanium tetrachloride reduction processes.

e. Group D - individuals having at least 10 years employment in production, but no more than 6 months employment in the titanium tetrachloride reduction processes.

Analysis of the data comparing these groups showed a large decrease in mean FVC and $\mathrm{FEV}_{1}$ for workers with a long history of work in the titanium tetrachloride reduction areas. A further regression analysis revealed that the loss of FVC and $\mathrm{FEV}_{1}$ per year worked is greater among these workers, is less severe among other production workers, and is least severe among non-production workers. This analysis was controlled for smoking.

The rate of loss of FVC after taking smoking into account was 45 $\mathrm{cc} / \mathrm{Yr}$.; a rate that over the course of 40 years of employment would cause a deficit of 1.8 liters from the FVC in addition to the losses due to aging and cigarette smoking. This would represent a significant loss of function and could result in considerable medical problems and symptoms. 
Page 10 - Health Hazard Evaluation Determination Report HE 79-17

VI. DISCUSSION

Excessive loss of pulmonary function was seen in all production groups. Even among non-production workers, loss of pulmonary function was suggested. The pattern of loss, primarily a restrictive form, was consistently present in all phases of the analysis. The use of non-production workers as a comparison group for production workers very likely led to under-estimation of the significance of the loss of pulmonary volumes seen among production workers. Comparison to a non-exposed group would very likely lead to larger differences and demonstrate a greater loss of pulmonary function due to production exposures.

The etiology of the pulmonary abnormalities is unclear from the information available. At the start of the study a review of the medical literature on the health effects of titanium and its compounds did not indicate that a serious risk should be expected. The environmental data, if the days during which the dati: vas collected are considered normal, does not indicate that the current working environment should be a factor. There was a preponderance of opinion among the workers that production was down on the days sampled; however, this claim could not be substantiated. On the contrary, RMI Company presented evidence verifying that production was typical. It is reasonable to assume that working conditions, due to technological advances and greater awareness of occupational safety and health through the history of RMI, have improved. Therefore, certain unmeasured working conditions in the past may have contributed to the development of pulmonary inpairment.

The chest $x$-ray abnormalities were not associated with the same exposures as the pulmonary function test abnormalities. The extensive grades of pleural thickening showed a clear relationship to employment in non-production areas, and the risk of deve?oping extensive pleural thickening increased with the duration of exposure. Asbestos exposure prior to RMI employment appeared to play a role in the development of pleural thickening, but was not sufficient to explain the pleural changes seen in the majority of workers affected. In fact, only four workers with pleural thickening had any known history of asbestos exposure before RMI. This history of asbestos exposure at RMI is unclear. Asbestos was used routinely in hot operations since the plant opened in 1957, and the extent of asbestos exposures during this period are not known. Because the extensive pleural changes were seen most commonly among maintenance workers who were likely to have the highest asbestos exposures, asbestos exposure at RMI may have played a role in the development of their pleural thickening. The observed pattern suggests that the limited and extensive pleural thickening are different processes and therefore represent different exposures. The lung biopsy findings of Elo(14) and Maatta(15) suggest that titanium dioxide causes localized increases in subpleural connective tissue and may accumulate in patches on the on the lung surface. Similar findings among rats also suggest that limited pleural changes may be seen in response to inhalation of titanium dioxide.(16) 
The loss of pulmonary function was greater among the titanium tetrachloride reduction workers. Exposures in that area include titanium tetrachloride, titanium chloride, titanium dioxide, metallic sodium, and welding fumes. Welding fumes are primarily respiratory irritants and therefore should cause obstructive changes (i.e. FEV 1 ). Titanium tetrachloride and sodium are also irritants. The medical Iiterature on the effects of titanium and titanium dioxide exposure does not demonstrate a consistent pulmonary effect, but some studies do suggest fibrotic changes. The latter are more consistent with the $x-r a y$ and pulmonary function changes found in this study.

Thus, although the exact exposure(s) causing the $x$-ray and pulmonary function changes at RMI could not be identified, past exposure to asbestos and current and/or past exposure to titanium/titanium dioxide are most likely responsible.

VIII。 RECOMMENDATIONS

A health hazard has existed at RMI and the health of the workers has been impaired. Actions should be taken which will prevent future inpairment of workers' health, and which will lead to earlier detection of hazardous exposures in the processes at RMI.

1. Actions should be taken to minimize skin contact with and inhalation of aerosols generated in the reduction, head welding, pot loading, and head removal operations. Frequent housekeeping should be performed to minimize the accumulation of dusts on work surfaces, rafters, and floors. Vacuum cleaning should be used rather than sweeping or blowing with compressed air. Exhaust ventilation should be in use during reduction and pot loading to prevent airborne dispersion of $\mathrm{TiCl}_{2}$ and related compounds. Spills and leaks of $\mathrm{TiCl}_{4}$ present an extreme health hazard. Maintenance of all piping, valves, pumps, and fittings used in the transport of this material should be performed on a schedule designed to anticipate and prevent leaks.

Local exhaust ventilation should be available and in use at all times during pot welding and head removal. Dusts and fumes released during head removal are strong skin irritants; protective clothing such as long sleeves and aprons should be available. Enclosure of head removal operations and installation of high volume exhaust ventilation for this area should be instituted if dust exposures cannot be significantly reduced through use of local exhaust ventilation and housekeeping. 
2. Chipping operations generate heavy dust loads which should be reduced through better housekeeping and the installation of high volume exhaust ventilation at each chipping station. Consideration should be given to reducing dust loads through the use of a water spray at the chipping face.

3. All waste asbestos should be disposed of according to EPA regulations. Pipe covering materials discarded haphazardly increase the potential for airborne fibers which can be inhaled.

4. Environmental sampling should be performed on a quarterly basis to detect to the presence of $\mathrm{TiO}_{2}, \mathrm{TiCl}_{4}$ and related compounds, titanium metal particulate, $\mathrm{NaO}$ and $\mathrm{NaOH}, \mathrm{HCl}$, and asbestos in the air in areas where they may reasonably be expected to be present: Records of environmental monitoring should be maintained in a manner that will allow the construction of exposure histories for all workers in the plant. Work records, likewise, should be maintained in a manner that will allow determination of the number of days spent in each work area and, when combined with environmental monitoring records, will allow determination of the intensity and duration of exposure in each work area.

5. A medical surveillance program should be adopted which includes periodic chest $x$-rays, physical examinations, and pulmonary function tests on each individual who spends time in the production areas. Pulmonary function tests should include measurement of the FVC and $\mathrm{FEV}_{1}$ on a spirometer which meets the American Thoracic Society Standardization of Spirometry recommendations (9). Any individual who demonstrates a loss in FVC exceeding $50 \mathrm{ml}$ per year for two successive years should have his spirometry repeated within one month of the second reading which demonstrates such loss. If the loss in FVC is confirmed to exceed $50 \mathrm{ml}$ per year for two years, the worker should be moved to a non-dusty job. In all cases, workers should be informed of their examination results.

6. Workers should be educated as to the importance of minimizing their dust exposures and the health effects of prolonged dust exposure. They should be instructed in the proper use of ventilation and in work practices which will minimize dust exposure.

7. Escape respirators already available to workers with potential for exposure to $\mathrm{TiCl}_{4}$ should be checked and maintained regularly. Dust respirators should be available to all workers who spend time in production areas. 
Page 13 - Health Hazard Evaluation Determination Report HE 79-17

8. The packing gland change operation in the reducer area should be closely supervised on very hot and humid days. It was reported that temperatures could reach $130^{\circ} \mathrm{F}$ at times. Temperature extremes such as this can cause heat related health problems. People who are unaclimitized to such conditions, who are overweight or who have been drinking alcohol the night before, are particularly susceptible. There are publications concerning hot environments that both management and workers should read $(17,18)$.

VIII。 REFEREENCES

1. "Threshold Limit Values for Chemical Substances and Physical Agents in the workroom Environment, with Intended Changes for 1979". American Conference of Governmental Industrial Hygienists (ACGIH) (1979) pg. 52.

2. Lawson, J.J. The Toxicity of Titanium Tetrachloride. Journal of Medicine, (Jan 1961). pg. 7-12.

3. Occupational Safety and Health Standards for General Industry. U.S. Department of Labor - (OSHA) Section 1910.1000 (Jan 1978). pg. 292.

4. IBID ACGIH, pg. 45 .

5. Revised Recommended Asbestos Standard. DHEW (NIOSH) Pub. No. 77-169, 1976.

6. IBID ACGIH, pg. 52 .

7. NIOSH Manual of Analytical Methods, 2nd Ed. Volumes 1-5. DHEW (NIOSH) Pub. No. 77-157A (April 1977).

8. Jacobson, G., Lainhjart, W.S. ILO U/C International Classification of Radiographs of the Pneumoconioses. Medical Radiography and Photography 48.3, 1972 .

9. Standardization of Spriometry. Statement: American Throacic Society. Am. Rev. of Resp. Dis. 119.5, 1979.

10. Knudson, R.J., Slatin, R.C., Lebowitz, M.D., Burrows, B. The Maximal Expiratory Flow-Volume Curve. Normal Standards, Variability, and Effects of Age. Amer. Rev. Resp. Dis. 113:587-600, 1976. 
11. Fine, L.J., and Peters, J.M. Respiratory Morbidity in Rubber Workers II. Pulmonary Function in Curing Workers. Arch. Environ. Hlth. 31: $6-10,1976$.

12. IBM Virtual Machine Facility/370: CMS User 's Guide Release 4 PLC 1. 2nd ed. International Business Machine, 1977.

13. Nie, N.H., Hull, C.H., Jenkins, J.G., Steinbrenner, K., Bent, D. Statistical Package for the Social Sciences - SPSS. New York, McGraw Hill, 1975.

14. Elo, R。, Maata, K。, Ursila, E., and Arstila, A.U. Pulmonary Deposits of Titanium Dioxide in Man. Arch. Path. 94:417-424, 1972.

15. Maata, K., Arstila, A.U. Pulmonary Deposits of Titanium Dioxide in Cytologic and Lung Biopsy Specimens. Laboratory Investigation $33: 342-346,1975$.

16. Christie, H., Mackay, R.J., Fisher, A.M. Pulmonary Effects of Inhalation of Titanium Dioxide by Rats. Amer. Ind. Hyg. Assoc. $J_{0}$ $24: 42$, 1963.

17. Criteria for a Recommended Standard . - Occupational Exposure to Hot Environments. DHEW (NIOSH) Pub. NO. HSM 72-10269. 1972.

18. Hot Environments. U.S. DOL-OSHA/U.S. DHHS-NIOSH Job Health Hazards Services 1980 .

IX. AUTHORSHIP AND ACKNOWLEDGEMENTS

Report Prepared By:

\author{
Clifford Moseley \\ Industrial Hygienist \\ Industrial Hygiene Section \\ Hazard Evaluations and \\ Technical Assistance Branch \\ Division of Surveillance, Hazard \\ Evaluations, and Field Studies \\ James Melius, M.D. \\ Chief, Hazard Evaluations and \\ Technical Assistance Branch \\ Division of Surveillance, Hazard \\ Evaluations, and Field Studies \\ NIOSH \\ Cincinnati, Ohio \\ David H. Garabrant \\ Lawrence J. Fine, M.D. \\ Harvard School of Public Health \\ Boston, Massachusetts
}


Originating Office:

Report Typed By:

\author{
Hazard Evaluations and Technical \\ Assistance Branch \\ Division of Surveillance, Hazard \\ Evaluations, and Field Studies \\ NIOSH \\ Cincinnati, Ohio \\ Linda Morris \\ Clerk-Typist \\ Industrial Hygiene Section
}

X. DISTRIBUTION AND AVAILABILITY OF REPFORT

Copies of this Determination Report are currently available upon request from NIOSH, Division of Technical Services, Information Resources and Dissemination Section, 4676 Columbia Parkway, Cincinnati, Ohio 45226. After 90 days, the report will be available through the National Technical Information Service (NTIS), 5285 Port Royal Road, Springfield, Virginia, 2215l. Information regarding its availability through NTIS can be obtained from the NIOSH Publications office at the Cincinnati address.

Copies of this report have been sent to:

1. Local 7-629, Oil, Chemical, and Atomic Workers Union

2. International Union, Oil, Chemical, and Atomic Workers

3. RMI Company

4. NIOSH, Region V

5. OSHA, Region $\mathrm{V}$

For the purposes of informing the affected employees, copies of the report shall be posted by the employer in a prominent place accessible to the employees, for a period of 30 calendar days. 
Figure I

TITANIUM SPONGE MANUFACTURING PROCESS

RMI Metals Reduction Plant

Ashtabula, Ohio

HE 79-17

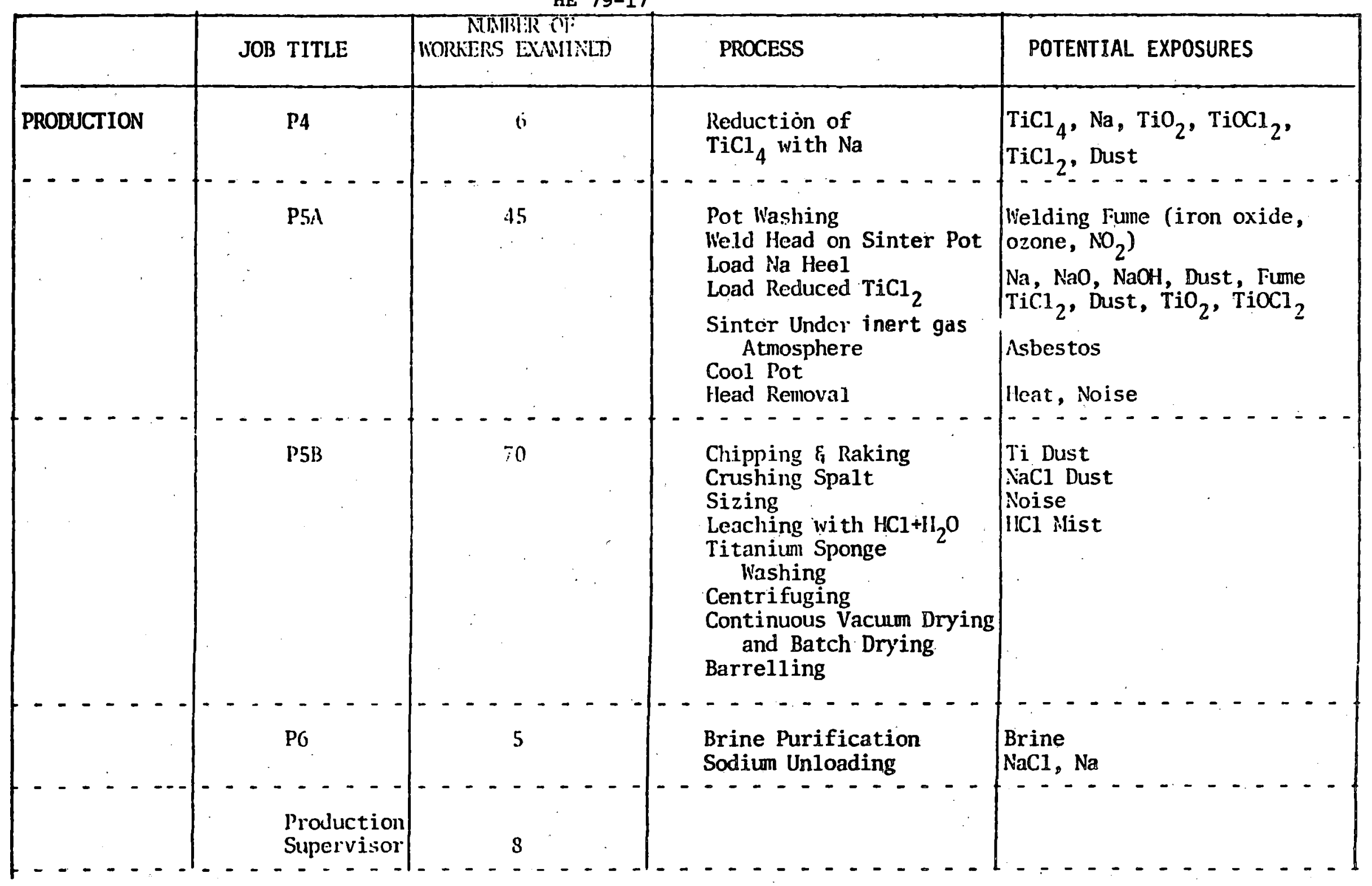


Figure 1, Continued

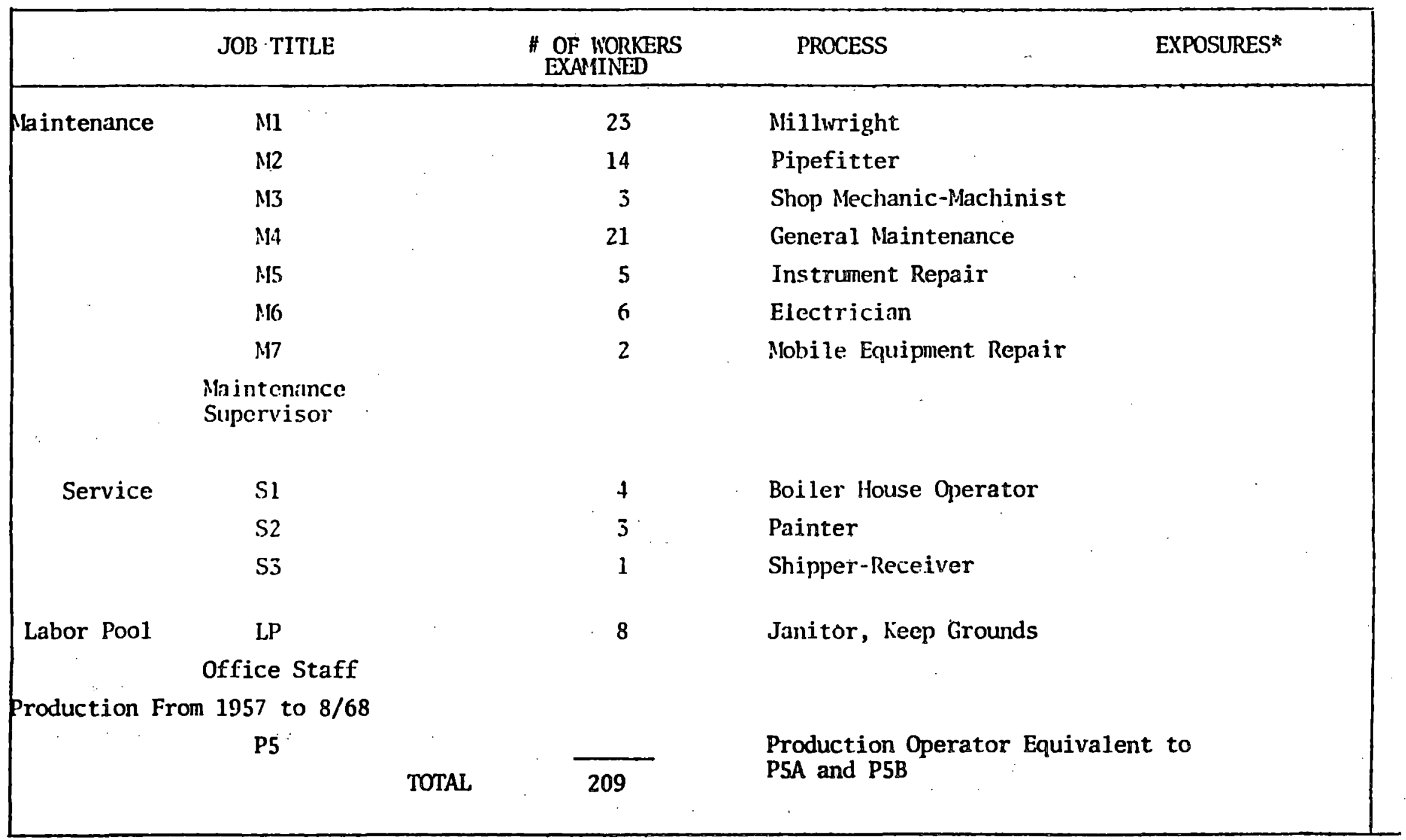

*All production materials intermittently 
Sukstances

\section{Titsnium}

(retal and oxide)

ritanive tetrachloride

None published

velding fume

ron and steel

Astestos

Fulsance Particulate

$5=9 / x^{3}$

0.1 fiber/cc

\section{Exposure Criteria}

$10 \mathrm{mg} / \mathrm{N}^{3}$ Total particulate

$5=g / \mathrm{M}^{3}$ Respirable particulate

Tone pubilshed

None published

$7 \mathrm{mg} / \mathrm{A}^{3}$

$5 \mathrm{mg} / \mathrm{m}^{3}$

2.0 fibers $/ \mathrm{cc}$

$15 \mathrm{mg} / \mathrm{M}_{3}^{3}$ total dust

$10 \mathrm{mg} / \mathrm{M}^{3}$. rotal particulate
Reference

ACGIA1

The 11 terature contalns conflicting reports of pulmonary fibrosis and decreased pulmonary function. Animal toxicity studies seem to indicate a low order of toxicity. Epidestudied exposures indicate pulmonary to multiple agents which could have contributed to the effect.

Layson ${ }^{2}$ then applled to the skin, $\mathrm{TiCl}_{4}$ produces burns as a. result of its thermal and corrosive effects. Exposure to heavy concentrations of $\mathrm{TiCl}_{4}$ fumes causes an acute preumonitis as a result of the corrosive effects of BCl liberated when the fumes contact the aqueous gections of the bronchial mucosa. a study of the long term pulmonary effects of lnhaling low concentrations noted fibrotic and infiltrative changes in one of 10 workers.

$\operatorname{ospa}^{3}$

acl is a strong local Irritant, producing alceration, scarring and burns of the skin and mucous membranes. In high concentrations, hCl may cause upper resplratory irritation,
laryngitis, and pulmonary edema.

ACGIB

Inhalation of Iron oxide fumes on dust may cause a benign pneumoconiosis (slderosis non-flbrotic, non-progressive). When metal fumes from welding are kept below the recommended criteria, other toxic substances found in the process uritege dioxide for exacple - are not a health $P$

N1OSE

Asbestos exposure results in progressive restrictive and abstructive defects in pulmonary function, pulmonary fibrosis and pleural thickening. Lung cancer, mesothelloma, and gastrointestinal cancer also result.

$5 \mathrm{mg} / \mathrm{M}^{3}$ respirable fraction
ACG186
Nuisance dusts have a long history of little adverse effects on lungs and do not produce significant organic disease or toxic ef fect when exposures are kept under reasonable control. Excessive concentrations may cause unpleasant deposits in the ears, eyes, and nasal passages and may caused by the rigorous skin cleaning procedure necessary for their removal. 
Table II

Sampling and Analytical Methodology(7)

RMI Metals Reduction Plant

Ashtabula, Ohio

HE 79-17

Substance

titanium compounds except $\left(\mathrm{TiCl}_{4}\right)$, nuisance particulate

welding fume

hydrochlorio acid

Destos

organic compounds
Sampling Method

preweighed DM800 filters on personal sampling pump operating at 1.5 (total particulate) and

1.7 (respirable particulate) liters/minute.

AA filters on personal sampling sampling pump operating at $1.51 \mathrm{pm}$

$0.1 \mathrm{~N}$ sodium hydroxide impinger, on general area sampling pump operating at $1.0 \mathrm{Ipm}$

AA filter in an open faced filter holder on an general area sampling pump operating at $1.5 \mathrm{lpm}$

phase contrast and electron microscopy

charcoal tube on a personal sampling pump operating at $0.2 \mathrm{lpm}$ (P\&CAM \#239)

Analytical Method

standard gravimetric procedures

atomic spectroscopy

(P\&CAM \#173)

(P\&CAM \#115)

(P\&CAM \#127) 
Personal Samples for Total and Respirable Particulate

\section{RII Metals Reduction Plant}

Ashtabula, Ohto

Une 25-29, 1979

\section{Sample Location}

Reducer - Process OP.

Reducer - Process OP.

Batch Drying - Sampler OP.

Blending - Blender OP.

Inspection Table \#1 - Inspector

Reducer - Changing Packing Gland

Reducer - Changing Packing Gland

old Chipping Deck - B gun

" " " - D gun

New Chipping Deck - F gun

Batch Drying - Process OP.

Reducer Area - Process OP.

old Chipping Deck - B gun

" $"$ - $C$ gun

New Chipping Deck - F gun

Inspection Table \#1 - Inspector

Head Cutting Area - Head Cutter

Reducer Area - Changing Packing Gland

Compactor Repatr

\section{B Hydroroom Repatr}

Con't Dryer, THCL pump Repair

Inspection Table - Inspector

Inspection/Screening Sampler

Batch Drying - Screening Sampler

Batch Drying - Process OP

01d Chipping Deck - C gun

". " "

Chipping Deck, Batch Drying Mechantc

Chippling Deck, Bateh Drylng

New Chippting opk

" Chipping Deck - G gun
Sample
Duration (min)

\section{7}

335
317

305
289

289
278

18
18

18
338

336

326
323

337

335
335

363
359
372

372

366
349
360

360

310

359

17
17

341

349
334

341

415
408

408
409

408

405
372

364
369

366
369

369
401
393

393
389

389
Samplé

Volume (M3)

$.51 / .57^{2}$

$.50 / .57$

$.48 / .54$

.49

.421 .47

$.03 / .03$
$.03 / .03$

$.03 \% .03$

$.51 \% .57$

$.50 \% .57$

$.49 \% .55$

$.48 / .55$

$.51 / .57$

$.50 / .57$

$.54 \% .62$

$.54 / .61$

$.56 / .63$

$.55 / .62$

$.52 / .59$

.541 .61

$.47 / .53$

.61

.03

.58
.59

.57

.58
$.62 / .71$

$.61 \% .69$

$.61 \% .70$

.617 .69

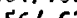

$.56 \% .63$

$.55 \% .63$

$.55 / .62$

$.55 / .63$

$.60 \% .68$

.591 .67

$.58 / .66$

$.45 / .57$
Concentration $\left(\mathrm{mg} / \mathrm{M}^{3}\right)^{1}$

Total Particulate Respirable Particulate
0.1

0.1

0.2

0.1

N.D.

0.6

0.5

0.1

0.4

N..

0.2

0.1

0.0
0.7

0.7
0.7

6.6

0.2

0.1

0.2

7.0
3.3

0.1

0.1

0.2

0.5

0.0

0.1

0.4

0.5

0.7

0.3

0.6

0.3

Recommended Exposure Criteria 5

Limlt of detection for analytical method (milligrams)

.01

1 mllligrams of substance per cubic meter of air sampled

denotes "Total" sample volume and "Respirable" sample volume; te Total/Respirable

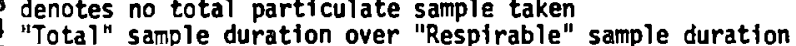

5 American Conference of Governmental Industrial Hygienists 


\section{TABLE IV}

\section{Personal Samples for Welding Fume \\ RMI Company Metals Reduction Plant \\ Ashtabula, Ohio \\ June 25-29, 1979 \\ HE $79-17$}

Sample
Pelding
"
"
"
"
"

ead cutter Head cutter

$$
\begin{gathered}
\text { (west) } \\
\text { (east) } \\
\text { (center) } \\
\text { (center) } \\
\text { (east) } \\
\text { (west) } \\
\text { (center) } \\
\text { (east) }
\end{gathered}
$$
Sample
Duration (min)

344

421

347

347

421

370

321

322

359

302
Sample Volume $\left(M^{3}\right)$

$$
\begin{aligned}
& .52 \\
& .63 \\
& .52 \\
& .54 \\
& .55 \\
& .56 \\
& .48 \\
& .48 \\
& .54 \\
& .46
\end{aligned}
$$

$\begin{array}{ll}0.08 & <.01 \\ 0.15 & .01 \\ 0.08 & <.01 \\ 0.67 & .05 \\ 0.11 & <.01 \\ 0.18 & <.01 \\ 0.09 & <.01 \\ 0.11 & <.01 \\ 0.01 & <.01 \\ 0.01 & <.01\end{array}$

Recommended Exposure Criteria ${ }^{2}$

Limit of detection for analytical method (milligrams)

$\begin{array}{ll}5 & 10 \\ .003 & .002\end{array}$

1 milligrams of substance per cubic meter of air sampled

2 American Conference of Governmental Industrial Hygienists 
Table $V$

Population Characteristics

Groups Determined by Work History (Mean + Standard Deviation)

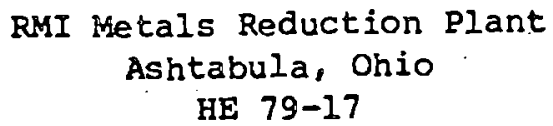

Group $1 \quad$ Group 2 Group $3 \quad$ Group $4 \quad$ Group 5

Ail

workers

$\mathrm{N}=209$

AGE, YRS.

$36.8 \pm 11.9$

Non-production Pro workers

$\mathrm{N}=58$

$42.3+13.3$
Titanium Tetra-

Production chloride reduction Other Productic workers workers

$\mathrm{N}=78$ workers $\mathrm{N}=7.3$

HEIGH, GS

$$
175.5 \pm 7.6 \quad 175.3 \pm 8.0 \quad 175.5 \pm 7.5 \quad 175.8 \pm 8.2 \quad 175.2 \pm 6.8
$$

$34.7 \pm 10.634 .5+10.0$

$35.0+11.4$

YRS. SMOKED

$$
12.6 \pm 12.5
$$

YRS. WORKED AT RM.

$$
8.8 \pm 8.1
$$

$16.5 \pm 15.6$

$11.0 \pm 10.5$

$11.0 \pm 11.010 .9 \pm 10.0$

YRS. HORKED IN

TITANILU TETRA.

$1.5 \pm 2.8$

$8.9 \pm 9.1$

$8.8 \pm 7.7$

$9.4 \pm 7.6$

$8.2 \pm 7.9$

CHLORIDE REDUCTION!

PROCESSES

TiE. MOPKE IM OTHEP PRODUCTION

$$
3.5 \pm 5.4
$$

0

$4.9 \pm 5.8$

$4.1 \pm 5.5$

$5.7 \pm 6.0$

YRS. WORKED IN ALI PRODUCTION

$$
5.0 \pm 6.4
$$

0

$6.9 \pm 6.6$

$8.2 \pm 6.9$

$5.7 \pm 6.0$

YRS. WORKED IN NONPRODUCTION

$$
3.8 \pm 6.8 \quad 8.9 \pm 9.1
$$

$1.9 \pm 4.3$

$1.2 \pm 2.4$

$2.5 \pm 5.6$

YRS. HORKED WITH

ASBESTOS BEFORE

RMI

$$
0.6 \pm 3.1 \quad 2.0 \pm 5.6 \quad 0.03 \pm 0.3 \quad 0.03 \pm 0.2 \quad 0.04+0.4
$$


Table VI

Symptoms: Comparison of Prevalence Among Exposure Groups

(Exposure Determined by Past Job History)

RMI Metals Reduction Plant

Ashtabula, Ohio

IE 79-17

Group ?

Group 2 Group 3

Group 4

Group 5

Titanium Tetra.

A9

rorkers

$\mathrm{N}=209$

Non-production Production chloride reduction workers

$\mathrm{N}=58$

workers

workers $\mathrm{N}=78$

workers $\mathrm{N}=73$

no.

no.

no. $\frac{\circ}{6}$ no.

n. \% no.

\%

PERSISTERST COUGH

178.1

3

5.2

149.3

45.1

10

13.7

PERSISTEIT PHLEGH

$28 \quad 13.4$

58.6

$23 \quad 15.2$

11 14.1

$12 \quad 16.4$

CHRONIC BRONCHI'TIS

178.1

23.4

$15 \quad 9.9$

79.0

811.0

MUEEZING EVER

12961.7

3255.2

9764.2

$46 \quad 59.0$

$51 \quad 69.9$

MEEING AOST DAYS OR NIGITS

$\begin{array}{llll}18 & 8.6 & 5 & 8.6\end{array}$

138.6

69.7

79.6

WHEEZING WITH SHCPTNESS OF BREATH $33 \cdot 15.8$

72.1

$26 \quad 17.2$

$11 \quad 14.1$

$15 \quad 20.5$

ONE CHEST ILLNESS

IS PAST 3 YRS.

$11 \quad 5.3 \quad 6.9$

74.6

79.0

00

MORE THAN ONE CHEST

ILLNESS IN PAST 3

YRS.

$\begin{array}{llll}15 & 7.2 & 2 & 3.4\end{array}$

138.6

67.6

79.6

HISTORY OF ASTHMA

104.8

23.4

85.3

$6 \quad 7.7$

$\begin{array}{ll}2 & 2.7\end{array}$

CURRENT SNOKERS

CIGARETTE
BIPE
CIGAR

$\begin{array}{rr}106 & 50.7 \\ 15 & 7.2 \\ 8 & 3.8\end{array}$

32
5
4

55.2
8.6
6.9

$74 \quad 49.0$

6.6
$34 \quad 43.6$
2.6
$2 \quad 2.6$
$40 \quad 54.8$
$8 \quad 11.0$
$\begin{array}{ll}2 & 2.7\end{array}$




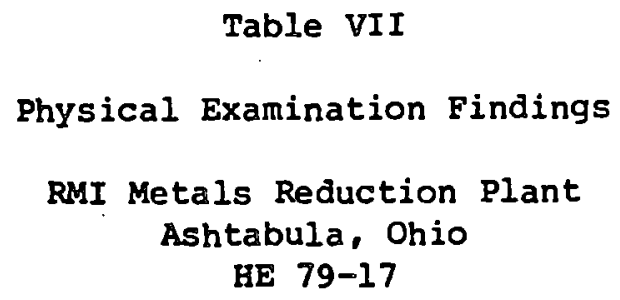

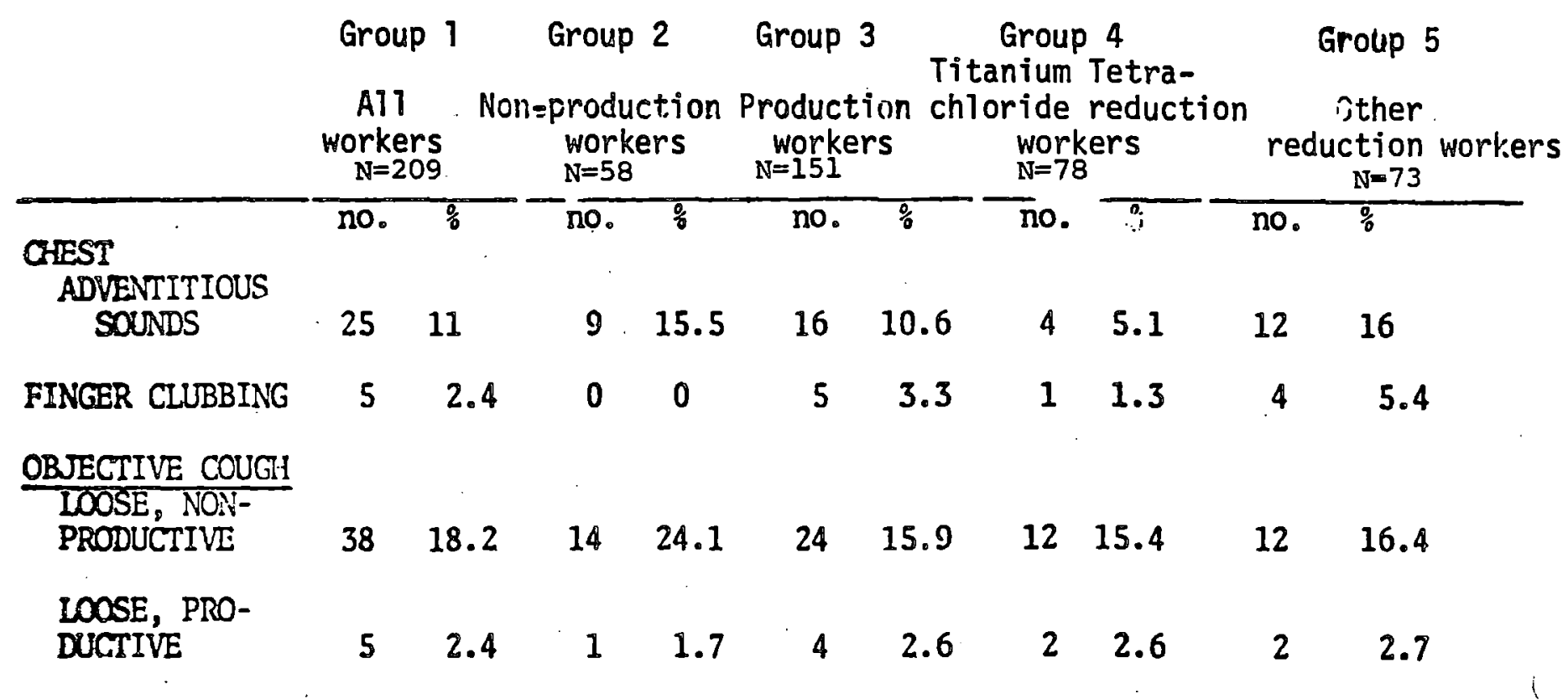


DEPARTMENT OF HEALTH AND HUMAN SERVICES

PUBLIC HEALTH SERYICE

CENTER FOR DISEASE CONTROL

NATIONAL INSTITUTE FOR OCCUPATIONAL SAFETY AND HEALTH

ROBERT A. TAFT LABORATORIES

467\% COLUMBIA PARKWAY, CINCINNATI, OHIO 45226

OFFICIAL BUSINESS

PENALTY FOR PRIVATE USE. $\$ 300$
POSTAGE AND FEES PAID U.S. DEPARTMENT OF HHS HHS 396 